\title{
1 Thermal properties of coal during low temperature oxidation using 2 a grey correlation method
}

3 Shuai-Jing Ren ${ }^{\mathrm{a}}$, Cai-Ping Wang, ${ }^{\mathrm{a}, \mathrm{b}}$, , Yang Xiao ${ }^{\mathrm{a}, \mathrm{b}, *}$, Jun Deng ${ }^{\mathrm{a}, \mathrm{b}}$, Yuan Tian ${ }^{\mathrm{c}}$, Jia-Jia Song,

$4 \quad$ Xiao-Jiao Cheng ${ }^{\mathrm{a}}$, Guo-Feng Sun ${ }^{\mathrm{d}}$

5 a School of Safety Science and Engineering, Xi'an University of Science and Technology, No. 58, Yanta Mid. Rd., Xi'an, Shaanxi

6710054, PR China

$7 \quad{ }^{b}$ Shaanxi Key Laboratory of Prevention and Control of Coal Fire, No. 58, Yanta Mid. Rd., Xi'an, Shaanxi 710054, PR China

$8{ }^{c}$ Institute of Energy and Sustainable Development (IESD), School of Engineering and Sustainable Development, De Montfort

University, Leicester LE1 9BH, UK

${ }^{d}$ Henan Institute of Geological Survey, Zhengzhou, Henan 450001, PR China

11 A B S T R A C T

The low temperature oxidation of coal is a contradictory and unified dynamic process of coexisting mass and heat transfer. The thermophysical properties are crucial during coal spontaneous combustion. In the current paper, the variations of moisture, ash, volatiles, fixed carbon and thermophysical properties (thermal diffusivity, specific heat and thermal conductivity) of three coal samples from $30{ }^{\circ} \mathrm{C}$ to $300{ }^{\circ} \mathrm{C}$ were studied, and their grey correlation was analyzed. The results indicated that with the increase of temperature, the free moisture of Coals A and B decreased first but then increased, while the free moisture of Coal C kept decreasing without a later increase. The variation of surface moisture was consistent with that of free moisture. The trend of volatiles and fixed carbon was completely the opposite, showing a significant negative correlation. Ash was less affected by temperature. Along with the rise of temperature, the thermal diffusivity of three coal

\footnotetext{
* Corresponding author at: School of Safety Science and Engineering, Xi'an University of Science and Technology, 58, Yanta Mid. Rd., Xi'an, Shaanxi 710054, PR China. E-mail address: 281448848@qq.com (C.P. Wang).

Corresponding author at: School of Safety Science and Engineering, Xi'an University of Science and Technology, 58, Yanta Mid. Rd., Xi'an, Shaanxi 710054, PR China. E-mail address: xiaoy@xust.edu.cn (Y. Xiao).
} 
1 samples decreased first but later increased, and the specific heat was always in a state of increasing.

2 The change in thermal conductivity was mainly affected by specific heat. By calculating the gray

3 correlation degree, the major factors affecting the thermophysical properties were obtained.

4 Keywords:

5 Heat transfer

6 Coal spontaneous combustion

$7 \quad$ Moisture

8 Thermal conductivity

9 Grey correlation 


\section{Nomenclature}

$X_{\mathrm{i}}(k) \quad k_{\text {th }}$ factor in the $i_{\text {th }}$ sequence

$x_{\mathrm{i}}(k) \quad$ dimensionless value of $X_{\mathrm{i}}(k) \quad$ sequence

$n \quad$ number of sequences $\quad M \quad$ average molar mass $(\mathrm{g} / \mathrm{mol})$

$m \quad$ number of factors in the sequence $\quad R \quad$ molar gas constant $(8.314 \mathrm{~J} /(\mathrm{mol} \mathrm{K}))$

$\xi_{\mathrm{i}}(k) \quad$ grey correlation coefficient of the $k_{\mathrm{th}}$ factor in the $i_{\text {th }}$ sequence Abbreviation

$x_{0}(k)$ dimensionless value of the $k_{\text {th }}$ factor of TD thermal diffusivity $\left(\mathrm{mm}^{2} / \mathrm{s}\right)$ the reference sequence $\quad \mathrm{SH} \quad$ specific heat $\left(10^{3} \mathrm{~J} /(\mathrm{kg} \mathrm{K})\right)$

a resolution coefficient ranging from TC thermal conductivity $(\mathrm{W} /(\mathrm{m} \mathrm{K}))$ $0-1$, usually taking $\rho=0.5$

\section{Introduction} coal fire, which causes a persistent and serious hazard [3] to the mining process: life loss of mine

5 workers, machinery damage and stoppage of further mining. Almost all major coal-producing countries (USA, Australia, China, South Africa, and India) have reported coal fire disasters [4-7], which cause huge waste of energy resources and pose a serious threat to the environment, human health and safety $[8,9]$. Low temperature oxidation of coal is the most important roots causing its spontaneous combustion. When coal comes in contact with oxygen, low temperature oxidation of coal always occurs, whether the coal is being mined, or being left naturally and unprocessed in a coal pile, or even during transportation. Such low temperature oxidation processes are extremely complicated involving physicochemical adsorption and oxidation reactions [10], and has therefore attracted much attention from the perspectives of safety, resources and the environment.

Wang et al. [11] analyzed the $\mathrm{CO}$ and $\mathrm{CO}_{2}$ production rates in oxidation and desorption experiments by gas chromatography, and explained the low temperature oxidation process of coal 
1 by proposing a multiple reaction mechanism. Li et al. [12] comparatively analyzed the heat release

2 rate of low temperature oxidation process of coal determined by various methods, and proposed a

3 method based on the thermogravimetric analysis (TGA) and differential scanning calorimetry (DSC)

4 to determine the low temperature oxidation kinetics of coal. Zhao et al. [13] studied the self-heating

5 characteristics of dry coal samples, and analyzed the effects of gas flow rate, particle size and

6 moisture content on the low temperature oxidation process of coal. Arisoy et al. [14] analyzed the

7 coal oxidation kinetics data and explained the changes of kinetics in the low temperature region by

8 deriving a new rate equation model.

9 Wang et al. [15] investigated the oxygen consumption characteristics of coal and oxidation

10 products, and revealed the mechanism of low temperature oxidation of coal. Chen et al. [16]

11 comparatively analyzed the thermochemical and kinetic characteristics of individual coal and mixed coal samples, and obtained their difference in low temperature oxidation. Zhang et al. [17] studied the dynamics and thermodynamics of low temperature oxidation process of coal based on the changes of elements, and discussed the mechanism of spontaneous combustion of coal. Itay et al. [18] measured the low temperature oxidation rate of coal, and found that the reaction of coal with oxygen is the main source of exotherm. Wang et al. [19] explored the variation of reactive functional groups in five coal samples (brown coal, gas coal, fat coal, and anthracite) during low temperature oxidation by using adiabatic oxidation tests, Fourier transform infrared (FTIR) and temperature programmed experiments. Kaji et al. [20] researched the low temperature oxidation of five different metamorphic coals in the temperature range of $30-250{ }^{\circ} \mathrm{C}$, and found that oxygen-containing functional groups play an important role in the low temperature oxidation process of coal.

The spontaneous combustion process of coal is essentially an unsteady heat and mass transfer 
1 process involving multiple internal heat sources. Low temperature oxidation of coal is an

2 irreversible reaction process involving extremely complex mechanisms, and its essence is to slowly

3 absorb oxygen from the environment, oxidize and release heat, causing coal to gradually accelerate

4 oxidation [16]. Low temperature oxidation of coal spans a wide range of temperatures (from room temperature to $\mathrm{ca} .30{ }^{\circ} \mathrm{C}$ ) $[12,21,22]$. When the heat generated by oxidation accumulates to such

6 an extent that heat cannot be dissipated in time, the temperature will gradually rise and eventually

7 lead to spontaneous combustion of coal. The heat transfer characteristics of coal is the major factor

8 affecting such heat dissipation. Therefore, studying the thermal characteristics of coal oxidation

9 process can help to understand the heat generation and dissipation characteristics of coal

10 spontaneous combustion process and provide a theoretical basis to prevention of spontaneous

11 combustion. The thermal conductivity (TC), specific heat (SH) and thermal diffusivity (TD) of coal are different in temperature sensitivity under different atmospheres [23-25]. The variation of SH

13 with temperature is usually contrary to that of TD with temperature [26,27]. There are large 14 differences in the thermophysical properties of coal with different metamorphic grades [28]. The thermophysical properties of coal are affected by many factors [29]. However, most researchers only qualitatively analyzed the relationship between these influencing factors and thermophysical

17 parameters, with very few studies showing a quantitative analysis which is important to study the 18 oxidation of coal. Therefore, the purpose of the current study is to: (1) analyze the change of 19 proximate analysis indexes (volatiles, moisture, fixed carbon, and ash) in coal in a temperature range of $30-300^{\circ} \mathrm{C},(2)$ investigate the variation of $\mathrm{TD}, \mathrm{SH}$, and $\mathrm{TC}$ of three coals with temperature,

21 (3) determine the major influencing factors affecting the thermal properties of coal through the gray 22 correlation analysis. The thermal properties of coal are extremely important attributes affecting spontaneous combustion, with changes in its intrinsic composition leading to large differences in 
1 thermal properties. Thus, the main focus of the current paper is to analyze the quantitative

2 relationship between coal thermophysical parameters and its internal components through a grey

3 correlation method, and to reveal the inherent causes of heat changes during low temperature

4 oxidation.

\section{Materials and methodology}

\subsection{Coal samples}

Bituminous coal is the most widely distributed and abundant coal in nature. It is used in a wide range of applications, such as boiler fuels, raw materials for the modern chemical industry, and civil fuels. Due to these characteristics, the proportion of bituminous coal spontaneous combustion is relatively large. Therefore, three different metamorphic levels of bituminous coal (Coal A, Coal B, and Coal C) were selected as research objects. Coal A, Coal B, and Coal C were taken from the coalmines of Aiweier, Liuhuanggou, and Sangshuping, respectively. To prevent oxidation of the coal samples, the collected coal samples were immediately wrapped with fresh films. Before the experiment, all the coal sample were first stripped of their oxide layers on the surfaces, and then pulverized into a powder having a particle size of 140-160 mesh. Such prepared coal samples were stored in dry sealed bags for later tests.

\subsection{Experiments on thermophysical parameters}

The apparatus used in the experiment was a laser-flash apparatus LFA 457 (Netzsch GmbH, Selb, Germany), the details of which were described by Min et al. [30]. The powdered coal samples were processed into tablets. To accommodate the size of the sample holder and prevent heat loss, the diameter and thickness of the coal tablets were made to $12.7 \mathrm{~mm}$ and $1.0 \mathrm{~mm}$, respectively. The tablets were placed in the testing apparatus through the sample holder, and tested at an air flow rate of $100 \mathrm{~mL} / \mathrm{min}$. Due to thermal inertia, a large heating rate would cause the coal sample to exceed 
1 the set temperature, resulting in irreversible changes in the coal molecular structure [23]. Therefore,

2 in order to ensure the stability and reliability of the experimental results, the heating rate was set to

$3 \quad 1{ }^{\circ} \mathrm{C} / \mathrm{min}$. The temperature measurement covered the range of $30-300{ }^{\circ} \mathrm{C}$, and a test point was set

4 for every $30{ }^{\circ} \mathrm{C}$ increment. Each coal tablet was tested three times at the set collection point, using

5 the average of three measurements as the thermophysical parameters for each temperature point $6 \quad[31]$.

\subsection{Proximate analysis experiment}

The proximate analysis indexes of coal were less sensitive to temperature in the range of 30

$9300{ }^{\circ} \mathrm{C}$. When the oxidation treatment temperature interval was small, the difference in the 10 proximate analysis indexes of coal was insignificant. Therefore, a larger temperature gradient was 11 selected to oxidize the coal samples. Each selected coal samples was divided into 5 groups, where coal samples were separately heated from room temperature to $90,150,210,270$, and $300{ }^{\circ} \mathrm{C}$ at

$131{ }^{\circ} \mathrm{C} / \mathrm{min}$ heating rate by a temperature programming device. Dry air was used as the purge gas, and 14 the flow rate was set to $100 \mathrm{~mL} / \mathrm{min}$. The treated coal samples were approximately analyzed by an automatic industrial analyzer, which provided the content of fixed carbon, ash, moisture and volatiles in the coal samples $[32,33]$. The results of the proximate analysis of the raw coal samples were presented in Table 1.

\section{Table 1}

\section{Results and discussion}

\subsection{Variation of proximate analysis indexes}

\subsubsection{Moisture}

As shown in Fig. 1, the change in capillary moisture of Coal $\mathrm{C}$ and Coal A before $270{ }^{\circ} \mathrm{C}$ was 
1 Coal B initially went down but then went up; that of Coal C gradually decreased first, then slightly

2 increased, and finally declined. The free moisture curve showed that before $150{ }^{\circ} \mathrm{C}$, the free

3 moisture of Coal A and Coal B gradually decreased with increasing temperature, and then gradually

4 increased after $150{ }^{\circ} \mathrm{C}$. The free moisture of Coal $\mathrm{C}$ gradually decreased before $210{ }^{\circ} \mathrm{C}$, slightly

5 increased in the temperature range of $210-270{ }^{\circ} \mathrm{C}$, and decreased again over $250{ }^{\circ} \mathrm{C}$. The moisture

6 in coal is composed of free moisture and bound moisture $[34,35]$. Free moisture refers to the water

7 adsorbed on the outer surface and into the internal pores of coal, which is combined with coal

8 physically not chemically. The free moisture further includes the capillary moisture adsorbed in the

9 capillary pores inside the coal particles and the surface moisture adsorbed on the surface of the coal

10 particles. The surface moisture was directly evaporated from the outer surface of the coal, and the

11 capillary moisture needed to be transported to the surface by capillary action for evaporation [36].

12 Surface moisture was more likely to evaporate than capillary moisture. Therefore, the capillary

13 moisture content of the coal sample was smaller than the surface moisture. The coal sample mainly

14 underwent a physical reaction before $150{ }^{\circ} \mathrm{C}$. With the rising temperature, the water evaporated gradually, causing a reduction in the free water content. After $150^{\circ} \mathrm{C}$, the carboxyl group, carbonyl group, phenolic group and aliphatic hydrogen in the coal were decomposed to produce moisture

17 [37,38], and the coal reacted with oxygen in the air to generate moisture. This caused the free 18 moisture of Coals $\mathrm{A}$ and $\mathrm{B}$ to increase with increasing temperature, and that of the Coal $\mathrm{C}$ to 19 decrease slowly and then gradually increase in the range from 150 to $270{ }^{\circ} \mathrm{C}$. After $270{ }^{\circ} \mathrm{C}$, the rate 20 of water evaporation was greater than that of water production, causing a prompt decrease of free 21 moisture of Coal C.

\section{$22 \quad$ Fig. 1}


From Fig. 2, the variation of volatiles with temperature was completely opposite to that of

2 fixed carbon, and their curves were in a symmetrical form except for Coal B. Before $90{ }^{\circ} \mathrm{C}$, due to

3 the lower temperature, coal and oxygen hardly reacted chemically, and the molecular structure of

4 coal did not decompose, so the volatiles changed little with temperature. The volatiles were mainly

5 pyrolysis products of organic matter, including gases generated by the cracking of various small

6 molecular structures in coal. The volatiles of Coals A and B gradually decreased in the temperature

7 range of $90-210{ }^{\circ} \mathrm{C}$, and began to rise after $210^{\circ} \mathrm{C}$. The explanation for this trend was as follows.

8 Before $210{ }^{\circ} \mathrm{C}$, some functional groups (methoxy, hydroxyl, and phenolic groups) in the coal

9 reacted with oxygen to form $\mathrm{H}_{2} \mathrm{O}, \mathrm{CO}$, and $\mathrm{CO}_{2}$ as the oxidation temperature increased. At the same

10 time, the bridging bonds, alkyl side chains, and other molecules in the coal were cleaved to produce

11 small molecular structures to volatilize out during the oxidation [39]. The oxidized coal samples

had less active components on the surface and formed a stable structure containing carboxyl or

carbonyl group [40,41], resulting in a decrease in volatiles generated during the pyrolysis. When the oxidation temperature exceeded $210{ }^{\circ} \mathrm{C}$, the cyclic macromolecular structure which was stable at low temperature in coal was decomposed and reacted with oxygen to form unsaturated hydrocarbons. These small molecular hydrocarbons produced alkane gas during pyrolysis, which

17 led to the gradual increase of volatiles. The volatiles change of Coals A and B was opposite to that of Coal $\mathrm{C}$, indicating that the molecular structure in Coal $\mathrm{C}$ was more reactive with oxygen than the other two. During the reaction between coal and oxygen, a large number of small volatile molecular structures were formed, leading to the gradual increase of volatiles before $270{ }^{\circ} \mathrm{C}$, which was

21 consistent with the research by Fredericks [42]. Volatiles and fixed carbon content can be used as 22 the basis for coal metamorphism [43-45]. As the degree of metamorphism deepened, the content of volatiles gradually decreased, and that of fixed carbon gradually increased. The variation of 
1 volatiles and fixed carbon with oxidation temperature further indicated that oxidation would affect

2 the degree of coal metamorphism. Organic matter was the main component of coal. The sum of the mass fractions of volatiles and fixed carbon in coal samples could approximately represent the total mass fraction of organic matter. Therefore, the volatiles content was opposite to the fixed carbon content. It is remarkable from Table 2 that the change of ash content of three coal samples was insensitive to the oxidation temperature. The ash in coal was derived from minerals which were mainly composed of muscovite, dolomite, quartz, pyrite, calcite, and kaolinite [46]. In the low temperature oxidation process, minerals mainly acted as catalysts [47], and underwent a series of physical and chemical reactions during the combustion process [48]. Therefore, the ash change was small within the temperature range of $30-300^{\circ} \mathrm{C}$.

Fig. 2

Table 2

\subsection{Variation of thermophysical parameters}

It is noticeable in Figs. 3 and 4 that with rising temperature, TD of three coals went down first but then up in the temperature range of $240-300{ }^{\circ} \mathrm{C}$. SH gradually increased with temperature, but the rate of increase decreased. Coal was an amorphous disordered solid material composed of a large number of different molecules, containing amorphous, crystals (calcite, quartz, kaolinite, and mica) and other impurities. Vibration modes in disordered materials included extendons and locons. Locons were localized and non-propagating, and had no significant contribution to heat transfer [49]. Therefore, heat transfer in coal was mainly dependent on extendons. Extendons contained two modes of propagation: propagons and diffusons. Propagons were low-frequency propagation modes that transfer energy through phonons, while diffusons acted as a localized mode of transferring heat through diffusion $[50,51]$ as the name suggests. At lower temperatures, the propagons propagation 
1 mode dominated, and heat propagated through the phonons eventually reaching a temperature

2 equilibrium. As the temperature increased, the number of phonons and collisions between phonons

3 increased, resulting in a decrease in the mean free path and the lifetime of phonons [52]. Therefore,

4 TD gradually decreased with increasing temperature. With further increasing temperature, the

5 oxidation reaction of coal gradually increased, causing the increase of coal disorder. The

6 contribution of the diffusons mode to heat transfer was gradually increased, and heat was further

7 propagated by diffusion. Therefore, TD decreased slowly until it increased.

$8 \quad$ Fig. 3

$9 \quad$ Fig. 4

SH represents the potential of a material to absorb and retain heat that is primarily stored by exciting a free mode of vibration in the structure of the material [31]. Below $300{ }^{\circ} \mathrm{C}$, the effect of temperature on SH could be explained by the solid molecular thermal theory of Einstein and Debye.

13 Due to the relatively small mass of carbon atoms and the strong binding force in the crystal lattice, the lattice vibration excitation was extremely large within the temperature range of $30-300{ }^{\circ} \mathrm{C}$ [53]. As temperature rose, the kinetic energy of coal molecules was gradually enhanced by absorbing energy, thus the molecules became more active and therefore the degree of freedom of vibration increased. The increase in $\mathrm{SH}$ with temperature was attributed to the increase in the degree of freedom of vibration [54]. With rising temperature, the oxygen-containing groups, side chains and other small molecular structures in the coal molecular structure began to crack, and the oxidation reaction of coal was therefore enhanced causing the increase of active structures in coal. The

21 transformation of molecular structure might have released additional vibration modes [55], so the 22 SH was always increasing. Since the absorption of energy by coal molecules was a gradual weakening process, the total energy in the coal sample gradually reached a saturated state, so SH 
increase rate gradually decreased. As the chemical reaction between coal and oxygen was further enhanced, the molecular structure of coal underwent irreversible changes, resulting in the decrease of $\mathrm{SH}$ in the high temperature region.

The variation of TC of Coals A and B was consistent. With the temperature rising constantly, their TC first increased, then reduced, and finally rose again. TC of Coal $\mathrm{C}$ was always increasing. Neglecting the change in density, TC varied with the product of TD and $\mathrm{SH}[56,57]$. Before $120{ }^{\circ} \mathrm{C}$, the decreasing rate of TD decreased gradually, while the increase of SH offset the decrease of TC caused by the decrease of TD. Therefore, TC of Coals A and B gradually increased. After $120{ }^{\circ} \mathrm{C}$, the influence of TD on TC was gradually increased, so TC was slightly reduced. With the further increase of temperature, TD began to increase gradually after decreasing to the minimal value. Under the influence of SH and TD, TC increased again. TC of Coal C was more affected by SH than by TD. It can be seen from the overall change that $\mathrm{TC}$ of three coal samples was more correlated with SH than TD. From a microscopic point of view, since the temperature characteristics of $\mathrm{TD}$ and $\mathrm{SH}$ were responded to various types of vibration states with temperature changes, the behavior of TC had the same origin [58]. Therefore, TC was affected by phonon scattering and vibrational freedom, and the change of TC was the result of the interaction between the two.

\subsection{Grey correlation analysis}

The changes of thermophysical parameters were influenced by moisture, ash, volatiles, and fixed carbon [59]. For moisture, it gradually evaporated with increasing temperature, resulting in the increase of coal porosity [60]. The originally filled moisture in the pores of coal was gradually replaced by air. The thermophysical properties of the moisture were greatly different from that of the air, which caused changes in the thermophysical properties of the coal. Ash was mainly derived from various minerals in coal, and the difference among the thermophysical properties of each 
1 mineral was also responsible for the change in the thermophysical properties of coal. The change in

2 volatiles and fixed carbon represented a change in the molecular structure of the coal, which was an

3 intrinsic cause of the difference in thermal properties. To obtain the main factors affecting the

4 thermal properties of coal, the correlation between the proximate analysis indexes and the

5 thermophysical parameters was analyzed according to the grey correlation degree theory [61]. The

$6 \mathrm{TD}, \mathrm{SH}$, and TC were used as the reference sequence, while the moisture, ash, volatiles, and fixed

7 carbon were used as the comparison sequence. Due to the different dimensions of the factors in

8 each sequence, comparisons between different sequences could not be made. Therefore, in order to

9 ensure the reliability of the result, the reference and comparison sequences were dimensionlessly

10 processed using Eq. (1).

$$
x_{i}(k)=\frac{X_{i}(k)}{\frac{1}{m} \sum_{k=1}^{m} X_{i}(k)},(i=0,1, \cdots, n ; k=1,2, \cdots, m)
$$

After the dimensionless processing, the correlation coefficient was calculated by Eq. (2), as shown in Fig. 5.

$$
\xi_{i}(k)=\frac{\min _{i} \min _{k}\left|x_{0}(k)-x_{i}(k)\right|+\rho \max _{i} \max _{k}\left|x_{0}(k)-x_{i}(k)\right|}{\left|x_{0}(k)-x_{i}(k)\right|+\rho \max _{i} \max _{k}\left|x_{0}(k)-x_{i}(k)\right|}
$$

\section{Fig. 5}

From Fig. 5, the correlation between the moisture at different temperatures and thermophysical parameters of the three coal samples was relatively low, while the correlation among ash, volatiles, fixed carbon, and thermophysical parameters was higher than that of moisture, which also showed a phasic characteristics. Therefore, the following analysis was focused on the relationship between three indicators (ash, volatiles, and fixed carbon) of proximate analysis with multiple thermophysical parameters. For Coal A, as the temperature increased, the correlation between the three indicators and TD increased first, then decreased, and finally increased again. The correlation 
1 between the three indicators with $\mathrm{SH}$ and TC increased first and then decreased. The correlation of

2 the thermophysical parameters of Coal B basically showed a trend of initial increase and subsequent

3 decrease. For Coal C, the change law of the correlation of TD was insignificant, and the correlation

4 between the three indexes and $\mathrm{SH}$, TC increased first but decreased subsequently. The correlation

5 degree between the reference sequence and the comparison sequence at each temperature was called

6 the correlation coefficient [62]. Because the number of information was excessively scattered, the overall comparison could not be performed. Thus, the degree of correlation between the comparison sequence and the reference sequence was obtained by Eq. (3). The grey correlation degree was displayed in Table 3.

$$
r_{i}=\frac{1}{m} \sum_{k=1}^{m} \xi_{i}(k),(i=1,2, \cdots n)
$$

\section{Table 3}

It is noted in Table 3 that moisture, ash, volatiles, and fixed carbon had different correlations with thermophysical parameters. The major influencing factors of TD of the three coals were volatiles, ash, and fixed carbon, respectively. For the same coal sample, the major influencing factors of SH were the same as that of TC. The change of fixed carbon had the greatest influence on $\mathrm{SH}$ and TC of coal A. The main influencing factors to $\mathrm{SH}$ and $\mathrm{TC}$ of Coals B and C were volatiles. TD represented the ability of the sample to be locally disturbed by temperature to reach equilibrium. Coal was of a highly heterogeneous mixture with extremely complex chemical structure. There were great differences in the characteristics of coal samples in different mining areas, so the factors influencing TD were rather different. From Fig. 3, both TC and SH showed an increasing tendency as the temperature rose. The change of the two was consistent and showed a strong correlation, which was why the major factors affecting the SH and TC of coal sample were chime with the same one. With rising of temperature, the increase in $\mathrm{SH}$ gradually became slower, and $\mathrm{SH}$ even 
1 decreased in high temperature region. This was because the average molar mass $\mathrm{M}$ gradually

2 increased with the release of volatiles, resulting in a decrease in the $3 \mathrm{R} / \mathrm{M}$ value, thus lowering the

$3 \mathrm{SH}$ [63]. Herrin et al. found that TC of bituminous coal was inversely proportional to the sum of

4 carbon and volatiles content [59]. Furthermore, it can be seen from the results of section 3.2 that the

5 thermophysical properties of coal were related to vibration and propagation modes which were

6 significantly impacted by the coal molecular structure. These further explained why SH and TC

7 were major affected by volatiles and fixed carbon.

\section{Conclusions}

In the current paper, the variations of moisture, ash, volatiles, fixed carbon, and thermophysical parameters of three coals at the range of $30-300{ }^{\circ} \mathrm{C}$ were studied and the correlation among them was analyzed. With increasing temperature, the free moisture of Coals A and B decreased first but then increased, while the free moisture of Coal $\mathrm{C}$ showed a continuous downward trend. Compared with capillary water, the overall change of surface moisture was consistent with that of free moisture. With the increasing temperature, the changes in volatiles of the three coals were inversely correlated with the change of fixed carbon. The ash in coal was derived from minerals and varied little with increasing oxidation temperature. TD decreased at first but then increased with increasing temperature. SH gradually increased with temperature, but its rate of increase decreased. With increasing temperature, TC of Coal $\mathrm{C}$ was always increasing. The variation of TC of Coals A and B was the same: first increased and then decreased. The overall trend of thermophysical parameters showed that TC of the three coals was more correlated with SH.

21 Through the gray correlation analysis, the quantitative relationship between the proximate analysis 22 indexes and the thermophysical parameters was established, and the main factors affecting the thermophysical properties were obtained. For the same coal sample, the main factors affecting SH 
1 and TC were the same. The main influencing factors to $\mathrm{SH}$ and TC of three coal samples were

2 concentrated approximately on two main analytical indicators: volatiles and fixed carbon. In

3 summary, through the above analysis method combining qualitative and quantitative, it was finally

4 found that the change of molecular structure inside coal was the main factor affecting

5 thermophysical properties, further revealing the mechanism of low temperature oxidation heat 6 transfer of coal.

\section{Acknowledgements}

This work was supported by the National Key R\&D Program of China (No. 2018YFC0807900), the National Natural Science Foundation of China (No. 51974233), Shaanxi

Key R\&D Program (No. 2017ZDCXL-GY-01-02-03), De Montfort University through its distinguished Vice-Chancellor 2020 Programme, and UK Science and Technology Facilities Council (STFC) through Batteries Early Career Researcher Award.

\section{References}

[1] Deng J, Lei C, Xiao Y, Cao K, Ma L, Wang W, et al. Determination and prediction on "three zones" of coal spontaneous combustion in a gob of fully mechanized caving face. Fuel 2018;211:458-70.

[2] Li QW, Xiao Y, Wang CP, Deng J, Shu CM. Thermokinetic characteristics of coal spontaneous combustion based on thermogravimetric analysis. Fuel 2019;250:235-44.

[3] Xiao Y, Ren SJ, Deng J, Shu CM. Comparative analysis of thermokinetic behavior and gaseous products between first and second coal spontaneous combustion. Fuel 2018;227:325-33.

[4] Engle MA, Radke LF, Heffern EL, O'Keefe JMK, Hower JC, Smeltzer CD, et al. Gas emissions, minerals, and tars associated with three coal fires, Powder River Basin, USA. Sci Total Environ 2012;420:146-59. 
1 [5] Deng J, Ren SJ, Xiao Y, Shu CM. Mechanical properties of coal and rock mass under thermo-mechanical coupling. Arab J Geosci 2019;12:398.

[6] Kuenzer C, Zhang J, Tetzlaff A, Dijk P, Voigt S, Mehl H, et al. Uncontrolled coal fires and their environmental impacts: investigating two arid mining regions in north-central China. Appl Geogr 2007;27:42-62.

[7] Deng J, Xiao Y, Li QW, Lu JH, Wen H. Experimental studies of spontaneous combustion and anaerobic cooling of coal. Fuel 2015;157:261-69.

[8] Song Z, Kuenze C. Coal fires in China over the last decade: a comprehensive review. Int J Coal Geol 2014;133:72-99.

[9] Zeng Q, Dong J, Zhao L. Investigation of the potential risk of coal fire to local environment: a case study of Daquanhu coal fire, Xinjiang region, China. Sci Total Environ 2018;640:1478-88.

[10] Yu J, Tahmasebi A, Han Y, Yin F, Li X. A review on water in low rank coals: The existence, interaction with coal structure and effects on coal utilization. Fuel Process Technol 2013;106:920.

[11] Wang H, Dlugogorski BZ, Kennedy EM. Analysis of the mechanism of the low-temperature oxidation of coal. Combust Flame 2003;134:107-17.

[12] Li B, Chen G, Zhang H, Sheng C. Development of non-isothermal TGA-DSC for kinetics analysis of low temperature coal oxidation prior to ignition. Fuel 2014;118:385-91.

[13] Zhao H, Yu J, Liu J, Tahmasebi A. Experimental study on the self-heating characteristics of Indonesian lignite during low temperature oxidation. Fuel 2015;150:55-63.

[14] Arisoy A, Beamish B. Reaction kinetics of coal oxidation at low temperatures. Fuel $2015 ; 159: 412-17$.

[15] Wang H, Dlugogorski BZ, Kennedy EM. Coal oxidation at low temperatures: oxygen 
consumption, oxidation products, reaction mechanism and kinetic modelling. Prog Energy Combust Sci 2003;29:487-513.

[16] Chen G, Ma X, Lin M, Lin Y, Yu Z. Study on thermochemical kinetic characteristics and interaction during low temperature oxidation of blended coals. J Energy Inst 2015;88:221-8.

[17] Zhang Y, Wu J, Chang L, Wang J, Xue S, Li Z. Kinetic and thermodynamic studies on the mechanism of low-temperature oxidation of coal: A case study of Shendong coal (China). Int $\mathbf{J}$ Coal Geol 2013;120:41-9.

[18] Itay M, Hill CR, Glasser D. A study of the low temperature oxidation of coal. Fuel Process Technol 1989;21:81-97.

[19] Wang D, Zhong X, Gu J, Qi X. Changes in active functional groups during low-temperature oxidation of coal. Min Sci Technol 2010;20:35-40.

[20] Kaji R, Hishinuma Y, Nakamura Y. Low temperature oxidation of coals: effects of pore structure and coal composition. Fuel 1985;64:297-302.

[21] Slovák V, Taraba B. Effect of experimental conditions on parameters derived from TG-DSC measurements of low-temperature oxidation of coal. J Therm Anal Calorim 2010;101:641-6.

[22] Worasuwannarak N, Nakagawa H, Miura K. Effect of pre-oxidation at low temperature on the carbonization behavior of coal. Fuel 2002;81:1477-84.

[23] Deng J, Li QW, Xiao Y, Shu CM. Experimental study on the thermal properties of coal during pyrolysis oxidation, and re-oxidation. Appl Therm Eng 2017;110:1137-52.

[24] Callanan JE, Sullivan SA, MacDonald RA. Experimental determination and modeling of the heat capacity of coal in various atmospheres. Int J Thermophys 1987;8:133-45.

[25] Gosset D, Guillois O, Papoular R. Thermal diffusivity of compacted coal powders. Carbon 1996;34:369-73. 
1 [26] Deng J, Li QW, Xiao Y, Shu CM, Zhang YN. Predictive models for thermal diffusivity and

[27] Tomeczek J, Palugniok H. Specific heat capacity and enthalpy of coal pyrolysis at elevated temperatures. Fuel 1996;75:1089-93.

[28] Zhumagulov MG. Experimental study of thermophysical properties of Shubarkol coal. Chem Technol Fuels Oils 2013;49:100-7.

[29] Deng J, Ren SJ, Xiao Y, Li QW, Shu CM. Thermal properties of coals with different metamorphic levels in air atmosphere. Appl Therm Eng 2018;143:542-9.

[30] Min S, Blumm J, Lindemann A. A new laser flash system for measurement of the thermophysical properties. Thermochim Acta 2007;455:46-9.

[31] Xiao Y, Yin L, Deng J, Wang CP, Shu CM. Thermophysical parameters of coal with various levels of preoxidation. J Therm Anal Calorim 2019;135:2819-29.

[32] Zhao J, Deng J, Wang T, Song J, Zhang Y, Shu CM, et al. Assessing the effectiveness of a high-temperature-programmed experimental system for simulating the spontaneous combustion properties of bituminous coal through thermokinetic analysis of four oxidation stages. Energy 2019;169:587-96.

[33] Deng J, Bai ZJ, Xiao Y, Laiwang B, Shu CM, Wang CP, et al. Thermogravimetric analysis of the effects of four ionic liquids on the combustion characteristics and kinetics of weak caking coal. J Mol Liq 2019;277:876-85.

[34] Lynch IJ, Webster DS. Effect of thermal treatment on the interaction of brown coal and water: a nuclear magnetic resonance study. Fuel 1982;61:271-5.

[35] Mraw SC, O'Rourke DF. Water in coal pores: the enthalpy of fusion reflects pore size 
distribution. J Colloid Interf Sci 1982;89:268-71.

[36] Arisoy A, Beamish B, Yoruk B. Moisture moderation during coal self-heating. Fuel 2017;210:352-8.

[37] Murray JB, Evans DG. The brown-coal/water system: Part 3. Thermal dewatering of brown coal. Fuel 1972;51:290-6.

[38] Shui H, Li H, Chang H, Wang Z, Gao Z, Lei Z, et al. Modification of sub-bituminous coal by steam treatment: caking and coking properties. Fuel Process Technol 2011;92:2299-304.

[39] Meng F, Yu J, Tahmasebi A, Han Y, Zhao H, Lucas J, et al. Characteristics of chars from low-temperature pyrolysis of lignite. Energy Fuels 2014;28:275-84.

[40] Wang H, Dlugogorski BZ, Kennedy EM. Analysis of the mechanism of the low-temperature oxidation of coal. Combust Flame 2003;134:107-17.

[41] Clemens AH, Matheson TW, Rogers DE. Low temperature oxidation studies of dried New Zealand coals. Fuel 1991;70:215-21.

[42] Fredericks PM, Warbrooke P, Wilson MA. Chemical changes during natural oxidation of a high volatile bituminous coal. Org Geochem 1983;5:89-97.

[43] Ulyanova EV, Molchanov AN, Prokhorov IY, Grinyov VG. Fine structure of Raman spectra in coals of different rank. Int J Coal Geol 2014;121:37-43.

[44] Arenillas A, Rubiera F, Pis JJ. Simultaneous thermogravimetric-mass spectrometric study on the pyrolysis behaviour of different rank coals. J Anal Appl Pyrol 1999;50:31-46.

[45] Nie B, Liu X, Yang L, Meng J, Li X. Pore structure characterization of different rank coals using gas adsorption and scanning electron microscopy. Fuel 2015;158:908-17.

[46] Dyk JCV, Benson SA, Laumb ML, Waanders B. Coal and coal ash characteristics to understand mineral transformations and slag formation. Fuel 2009;88:1057-63. 
1 [47] Herman RG, Simmons GW, Cole DA, Kuzmicz V, Klier K. Catalytic action of minerals in the low temperature oxidation of coal. Fuel 1984;63:673-8.

[48] Hurley JP, Schobert HH. Ash formation during pulverized subbituminous coal combustion. 1. Characterization of coals, and inorganic transformations during early stages of burnout. Energ Fuel 1992;6:47-58.

[49] Leitner DM. Vibrational energy transfer and heat conduction in a one-dimensional glass. Phys Rev B 64:094201.

[50] Allen PB, Feldman JL, Thermal conductivity of disordered harmonic solids. Phys Rev B 1993;48:12581-8.

[51] Allen PB, Feldman JL, Fabian J, Wooten F. Diffusons, locons and propagons: Character of atomie yibrations in amorphous Si. Philos Mag B 1999;79:1715-31.

[52] Branlund JM, Hofmeister AM. Thermal diffusivity of quartz to $1,000{ }^{\circ} \mathrm{C}$ : effects of impurities and the $\alpha-\beta$ phase transition. Phys Chem of Miner 2007;34:581-95.

[53] Melchior E, Luther H. Measurement of true specific heats of bituminous coals of different rank, and of a high-temperature coke, in the temperature range $30-350{ }^{\circ} \mathrm{C}$. Fuel 1982;61:1071-9.

[54] Maloney DJ, Sampath R, Zondlo JW. Heat capacity and thermal conductivity considerations for coal particles during the early stages of rapid heating. Combust Flame 1999;116:94-104.

[55] Deng J, Ren SJ, Xiao Y, Li QW, Shu CM, Bai GY. Thermophysical properties of coal during low temperature oxidation under different oxygen concentrations. Thermochim Acta 2019;676:186-97.

[56] Deng J, Li QW, Xiao Y, Wang CP, Shu CM. Thermal diffusivity of coal and its predictive model in nitrogen and air atmospheres. Appl Therm Eng 2018;130:1233-45.

[57] Wen H, Lu J, Xiao Y, Deng J. Temperature dependence of thermal conductivity, diffusion and 
specific heat capacity for coal and rocks from coalfield. Thermochim Acta 2015;619:41-7.

[58] Abdulagatov IM, Abdulagatova ZZ, Kallaev SN, Bakmaev AG, Ranjith PG. Thermal-diffusivity and heat-capacity measurements of sandstone at high temperatures using laser flash and DSC methods. Int J Thermophys 2015;36:658-91.

[59] Herrin JM, Deming D. Thermal conductivity of U.S. coals. J Geophys Res 1996;101:25381-6.

[60] Clauser C, Huenges E. Thermal conductivity of rocks and minerals. Rock Physics and Phase Relations: A Handbook of Physical Constants 1995;3:105-26.

[61] Chiang KT, Chang FP. Optimization of the WEDM process of particle-reinforced material with multiple performance characteristics using grey relational analysis. J Mater Process Technol 2006;180:96-101.

[62] Cui C, Zhao X. Analysis and trace of the influencing factors of oilfield production decline based on the grey interconnect analysis method. 2010 2nd International Conference on Computer Engineering and Technology. DOI:10.1109/ICCET.2010.5485619.

[63] Hanrot F, Ablitzer D, Houzelot JL, Dirand M. Experimental measurement of the true specific heat capacity of coal and semicoke during carbonization. Fuel 1994;73:305-9. 


\section{$1 \quad$ List of tables}

2 Table 1

3 Proximate analysis of three raw coal samples (air-dried basis, mass $\%$ ).

4 Table 2

5 Variation of ash corresponding to temperatures for three coal samples.

6 Table 3

7 Grey correlation degree of three coals. 


\section{$1 \quad$ Table 1}

2 Proximate analysis of three raw coal samples (air-dried basis, mass\%).

\begin{tabular}{ccccc}
\hline Specimen & Moisture & Ash & Volatiles & Fixed carbon \\
\hline Coal A & 0.18 & 9.34 & 21.58 & 68.90 \\
Coal B & 0.67 & 30.80 & 12.19 & 56.34 \\
Coal C & 1.74 & 8.47 & 24.87 & 64.92 \\
\hline
\end{tabular}




\section{$1 \quad$ Table 2}

2 Variation of ash corresponding to temperatures for three coal samples.

\begin{tabular}{cccccccc} 
& \multicolumn{9}{c}{ Ash (\%) } & Maximum \\
\cline { 2 - 6 } Specimen & & \multicolumn{9}{c}{} & \\
ncoal A & 9.34 & 9.16 & 9.10 & 9.06 & 8.73 & 8.96 & $6.63 \%$ \\
Coal B & 30.80 & 30.99 & 30.63 & 30.04 & 30.02 & 29.95 & $2.76 \%$ \\
Coal C & 8.47 & 8.83 & 8.72 & 8.43 & 8.57 & 9.07 & $7.08 \%$ \\
\hline
\end{tabular}

3 


\section{$1 \quad$ Table 3}

2 Grey correlation degree of three coals.

\begin{tabular}{|c|c|c|c|c|c|}
\hline \multirow{2}{*}{ Specimen } & \multirow{2}{*}{ Thermophysical parameters } & \multicolumn{4}{|c|}{ Grey relational grade } \\
\hline & & Moisture & Ash & Volatile & Fixed carbon \\
\hline \multirow{3}{*}{ Coal A } & Thermal diffusivity & 0.5421 & 0.8986 & 0.9022 & 0.8764 \\
\hline & Specific heat & 0.5400 & 0.7601 & 0.7534 & 0.7802 \\
\hline & Thermal conductivity & 0.5120 & 0.8977 & 0.9057 & 0.9275 \\
\hline \multirow{3}{*}{ Coal B } & Thermal diffusivity & 0.5430 & 0.6656 & 0.6133 & 0.6376 \\
\hline & Specific heat & 0.4926 & 0.6772 & 0.7301 & 0.7012 \\
\hline & Thermal conductivity & 0.4965 & 0.8547 & 0.8996 & 0.8730 \\
\hline \multirow{3}{*}{ Coal C } & Thermal diffusivity & 0.5730 & 0.7251 & 0.6300 & 0.7725 \\
\hline & Specific heat & 0.4697 & 0.6585 & 0.7400 & 0.6407 \\
\hline & Thermal conductivity & 0.4898 & 0.7221 & 0.8397 & 0.7027 \\
\hline
\end{tabular}




\section{$1 \quad$ Figure captions}

2 Fig. 1. Change in moisture content of three coals at corresponding temperatures.

3 Fig. 2. Change in volatiles and fixed carbon of three coals at corresponding temperatures.

4 Fig. 3. Temperature dependence of thermophysical parameters for coal samples.

5 Fig. 4. Rate of variation for the thermophysical parameters of coal samples.

6 Fig. 5. Correlation coefficient between thermophysical parameters and proximate analysis indexes

7 of coal samples. 


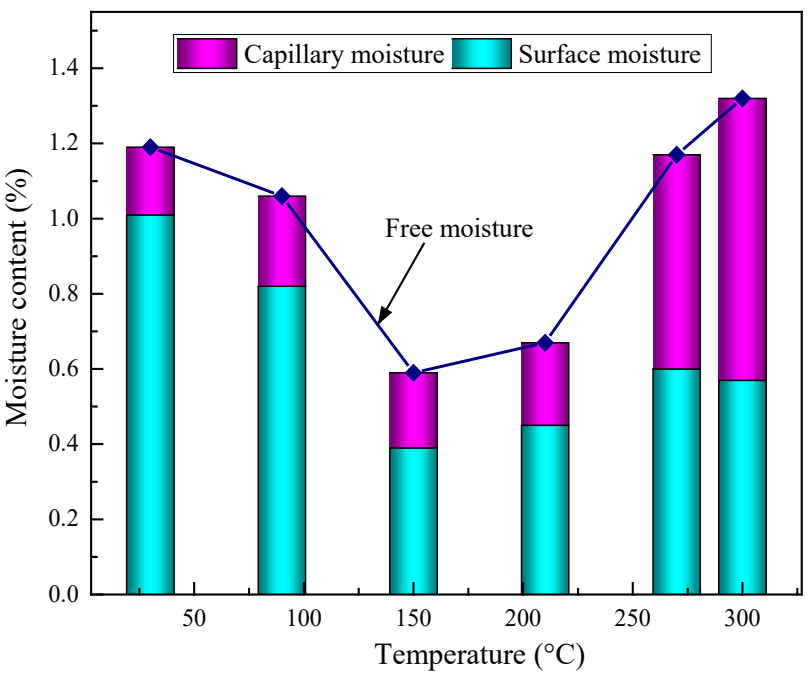

Coal A

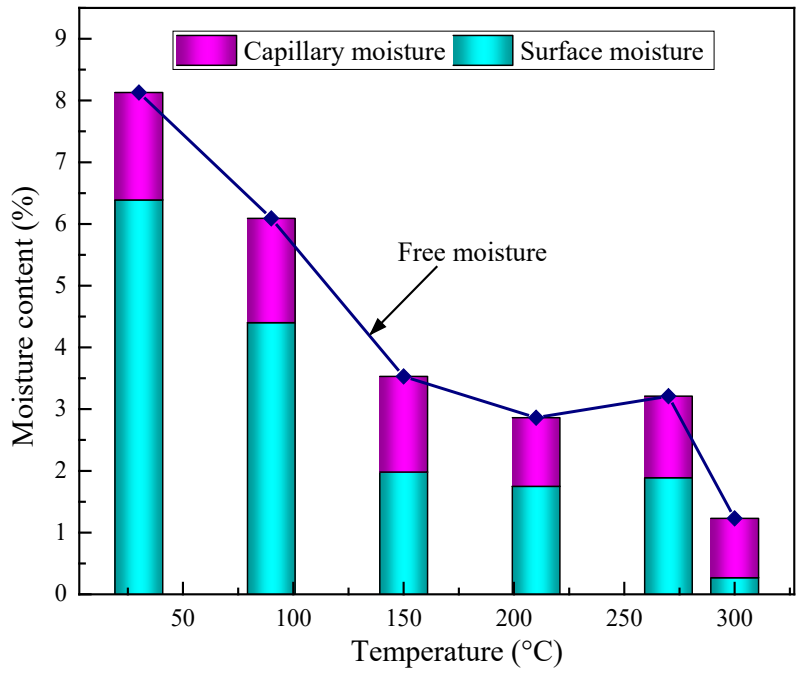

Coal C

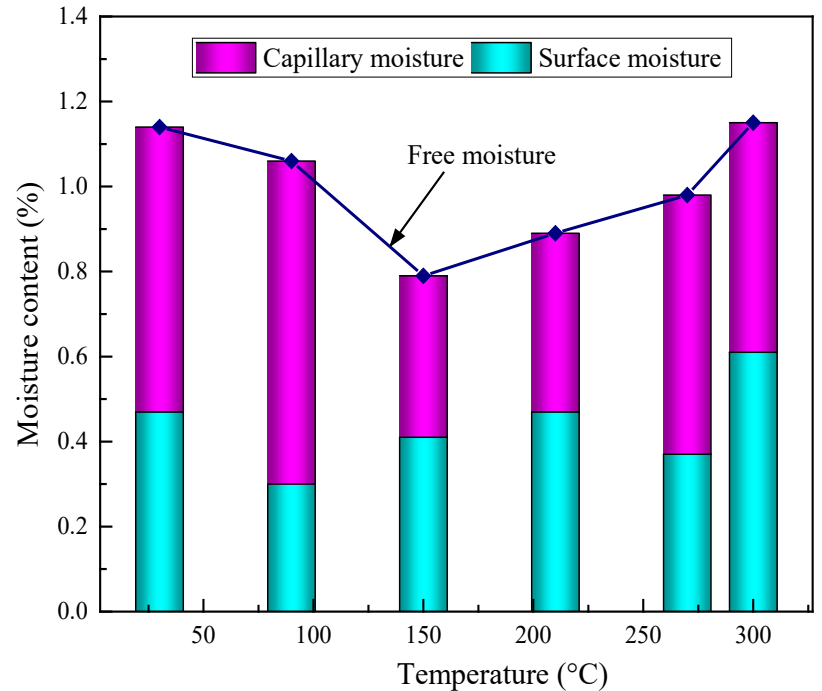

Coal B

5 Fig. 1. Change in moisture content of three coals at corresponding temperatures. 


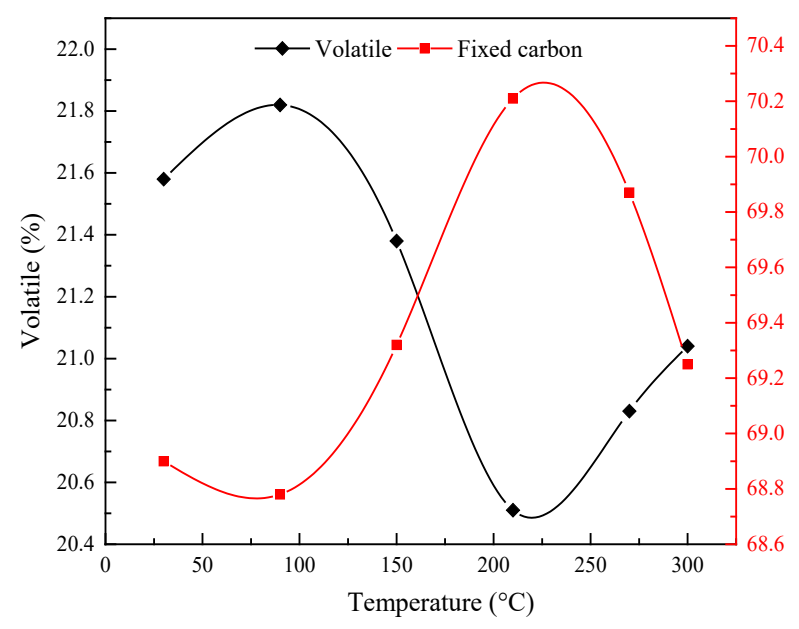

Coal A

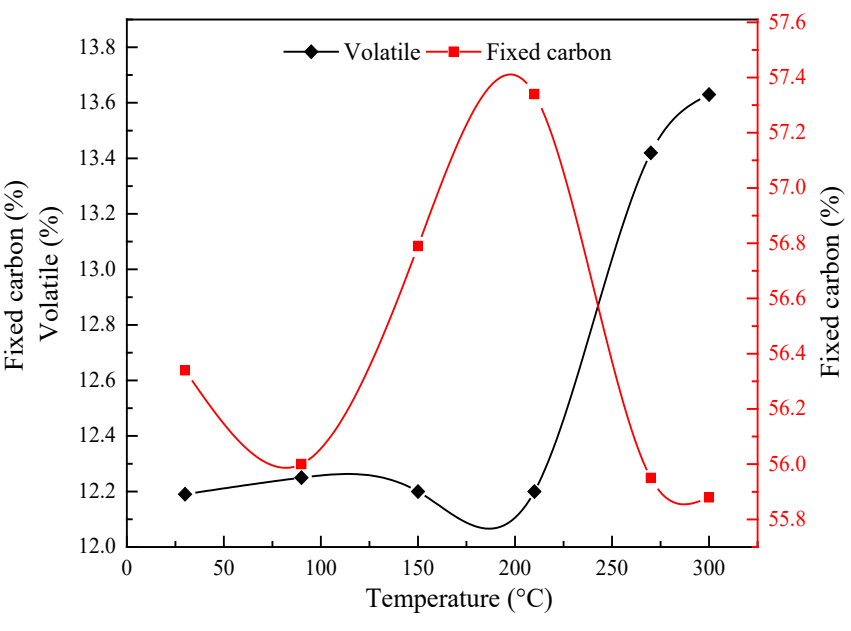

Coal B

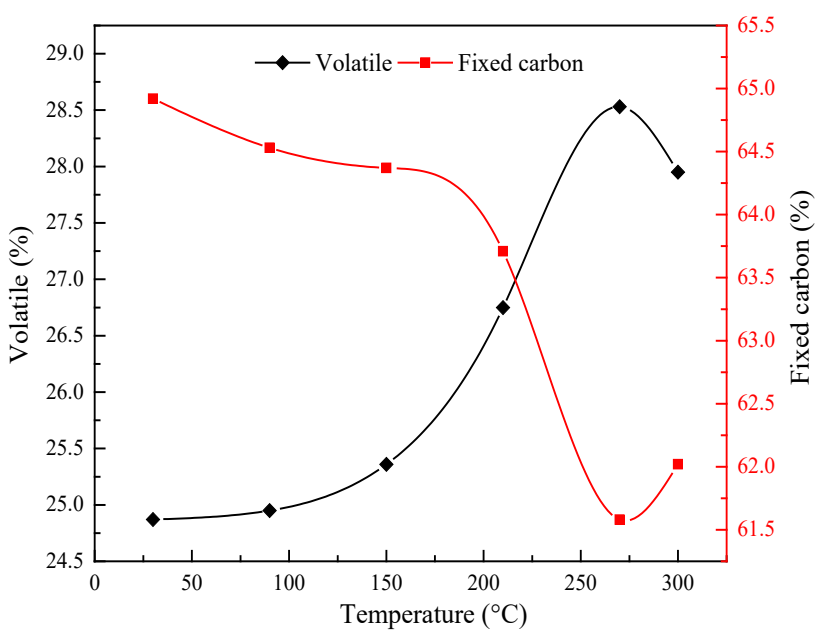

Coal C

5 Fig. 2. Change in volatiles and fixed carbon of three coals at corresponding temperatures. 


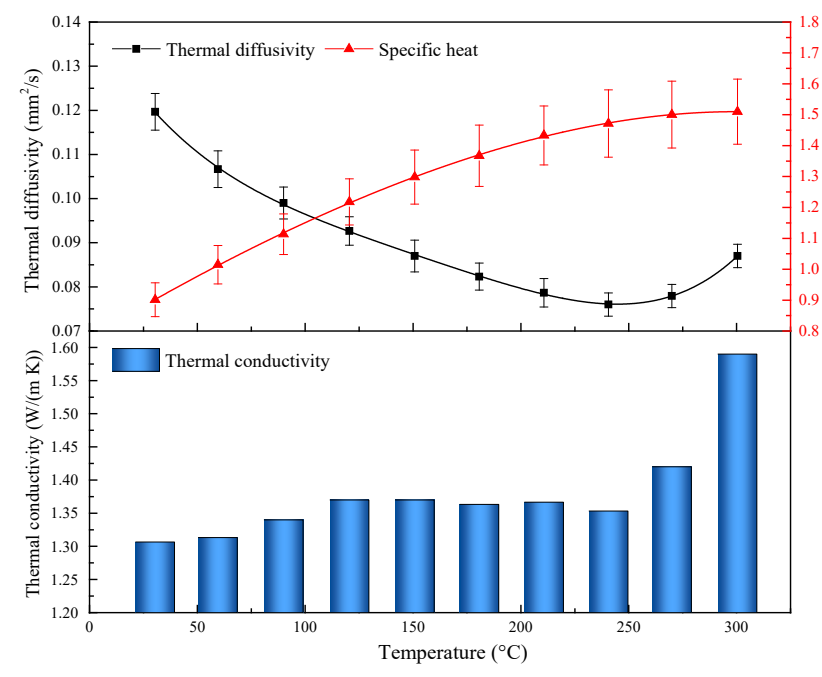

2

Coal A

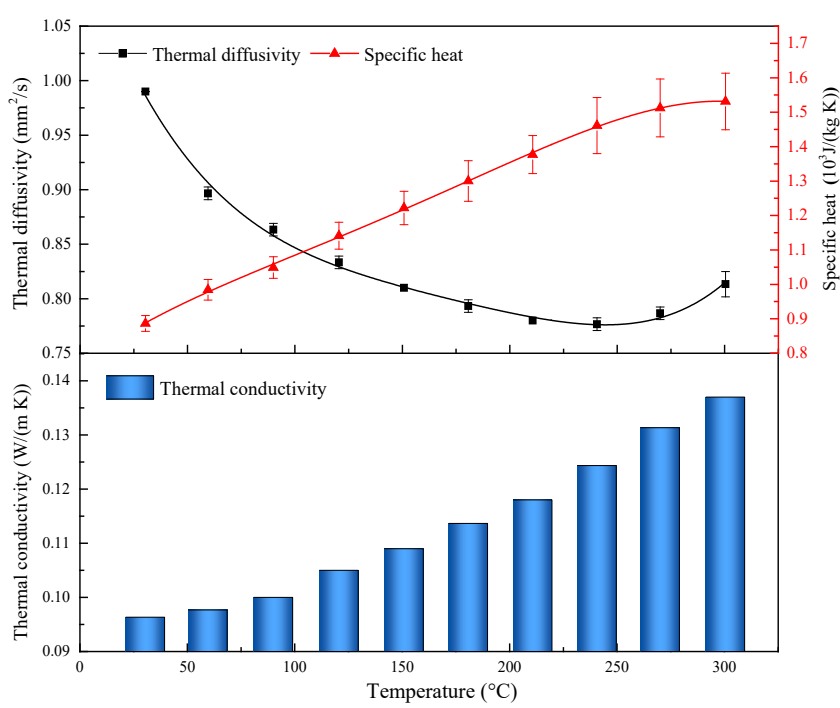

Coal C

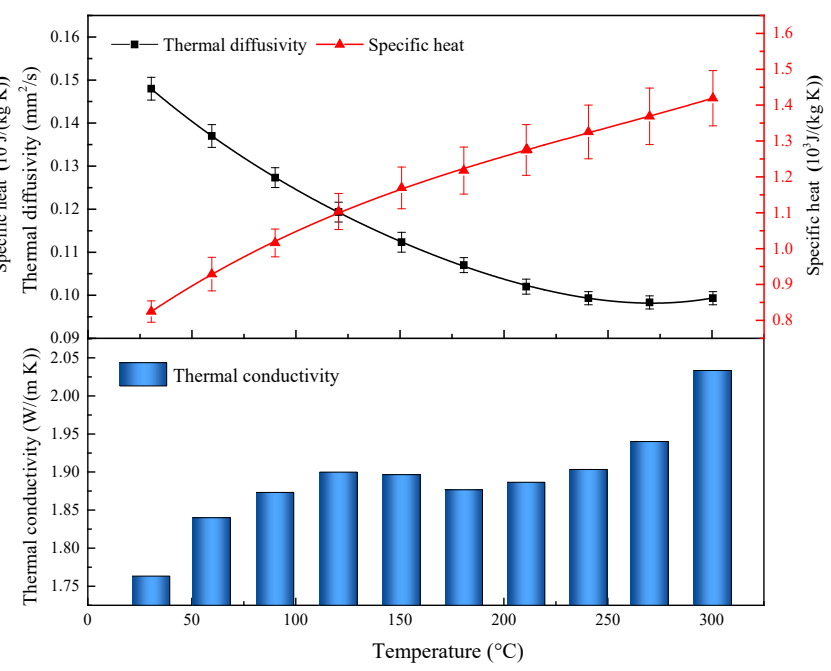

Coal B

3

Fig. 3. Temperature dependence of thermophysical parameters for coal samples. 


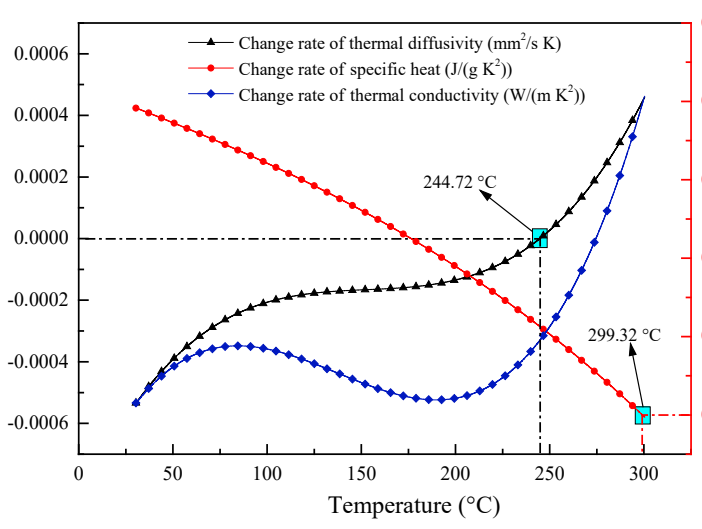

Coal A

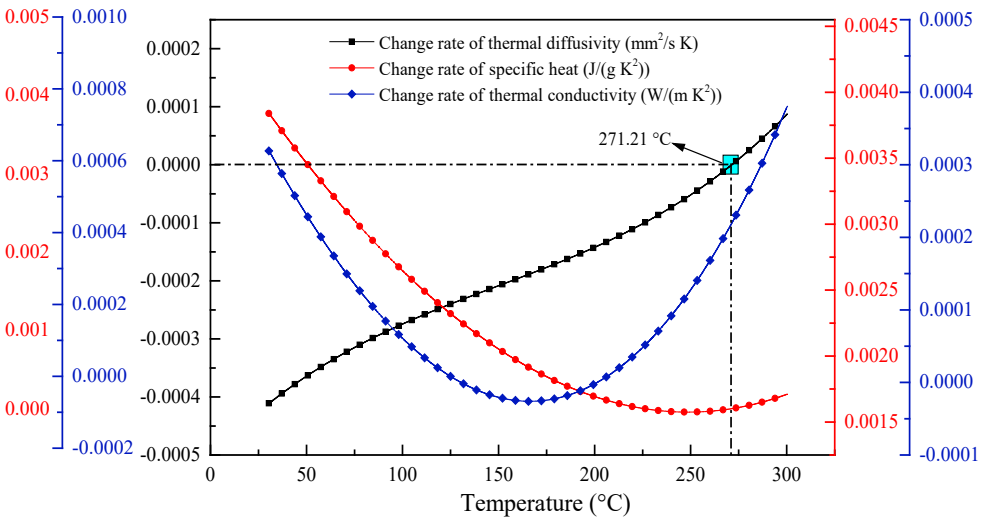

Coal B

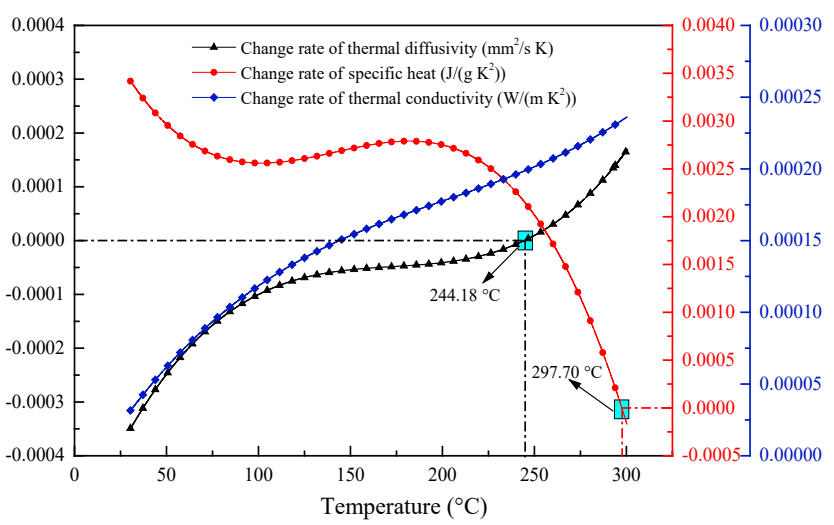

Coal C

5 Fig. 4. Rate of variation for the thermophysical parameters of coal samples. 


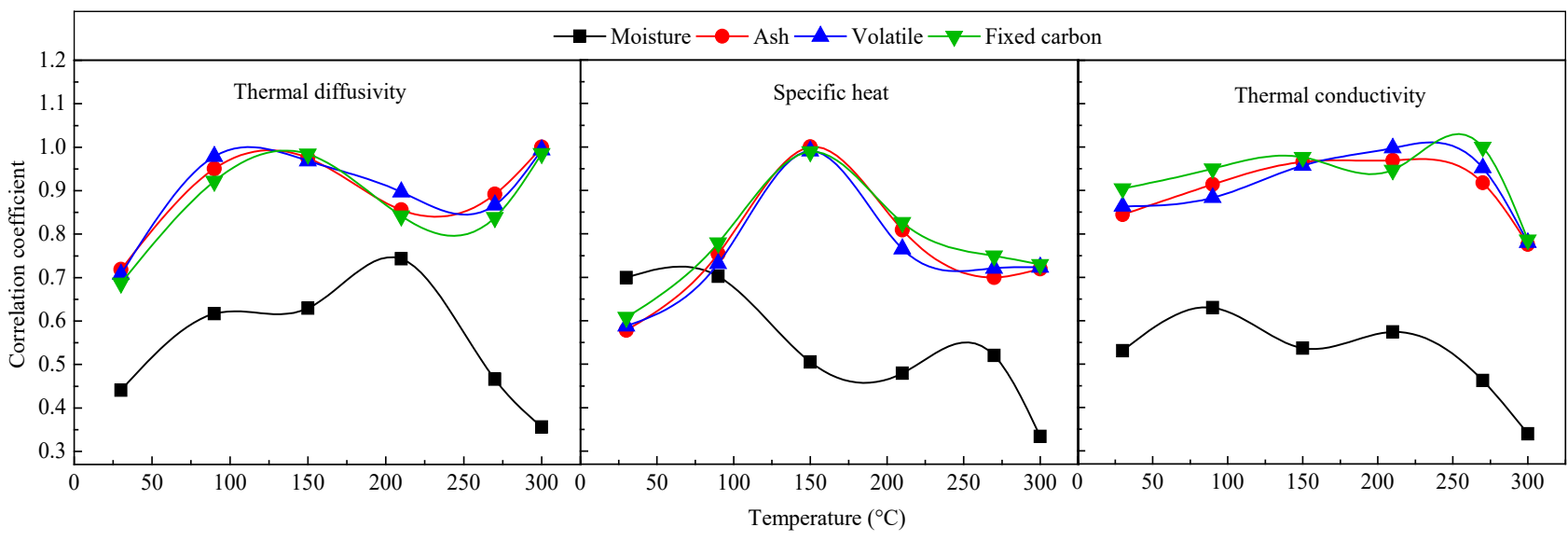

Coal A

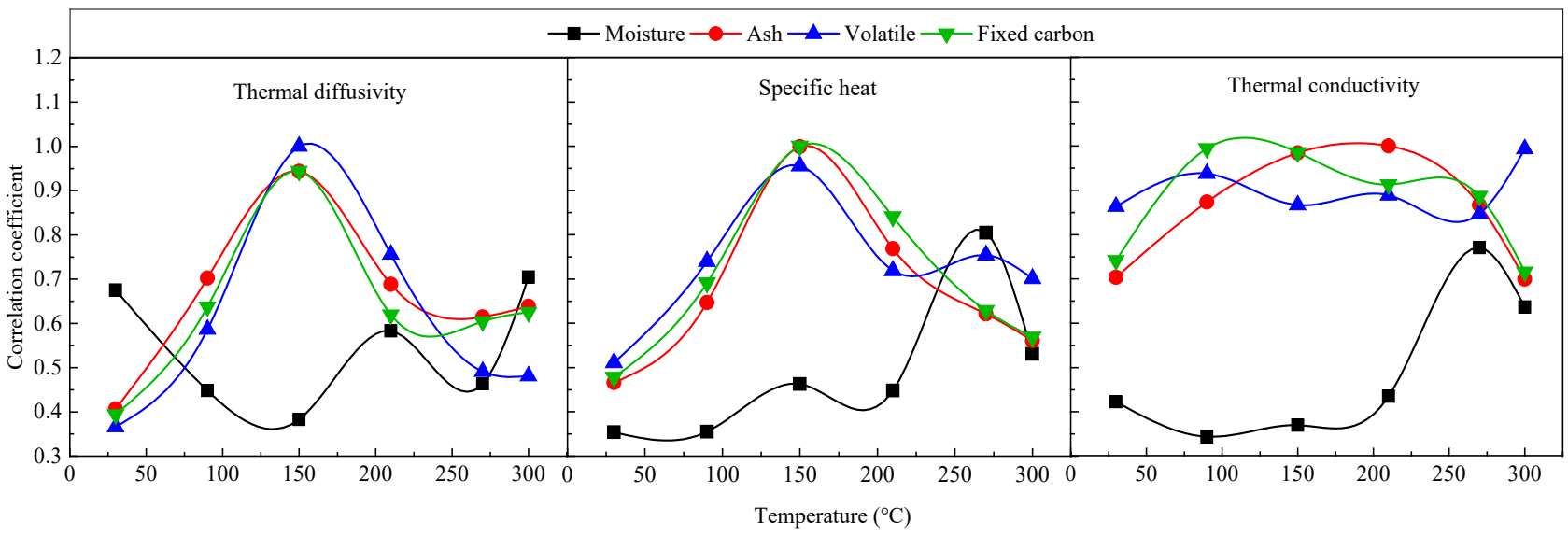

Coal B

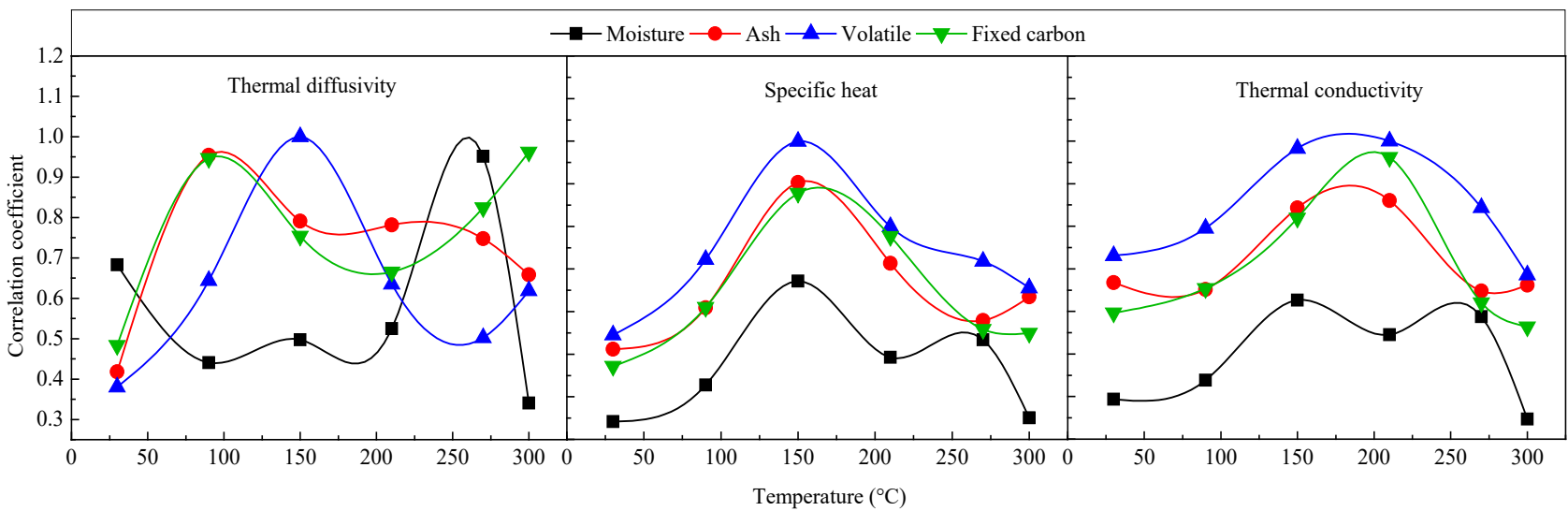

Coal C

Fig. 5. Correlation coefficient between thermophysical parameters and proximate analysis indexes of coal samples. 